\title{
Evaluation of PEFC Membrane based on Cross-linked PTFE by EB Grafting: Effect of Thickness for FC Performance
}

\author{
S. Hiraiwa ${ }^{1}$, T. Yoshikawa ${ }^{1}$, A. Oshima $^{2}$ and M. Washio ${ }^{1}$ \\ 1: Research Institute for Science and Engineering, Waseda University \\ 3-4-1 Okubo, Shinjuku-ku, Tokyo 169-0072, Japan \\ 2: Institute of Scientific and Industrial Research, Osaka University \\ 8-1 Mihogaoka, Ibaraki-shi, Osaka 567-0047, Japan
}

\begin{abstract}
The performance of a polymer electrolyte fuel cell (PEFC) was affected by the thickness of the thin proton exchange membrane (PEM). The PEMs with the different thickness were prepared by radiation induced grafting of styrene into the radiation-cross-linked polytetrafluoroethylene (RX-PTFE) membrane prepared from PTFE dispersion, and then sulfonated. The wet thicknesses of the obtained thin PEMs were lower than $25 \mu \mathrm{m}$. A PEM based on a $50 \mu \mathrm{m}$ PTFE film, with the wet thickness of 73 $\mu \mathrm{m}$, was also prepared under the same procedure for the comparison. The obtained PEMs were characterized in term of gas cross-over. The surface of platinum / carbon electrodes was coated with Nafion ${ }^{\circledR}$ dispersion, and then membrane electrode assembles (MEAs) were prepared by the hot-pressing. The polarization curves and electrochemical impedances of the thin PEMs in a single fuel cell were analyzed. As a result, the cell performance of the MEA based on thinner PEM tended to give higher power density and current density. On the other hand, the performance of the thinnest PEM $(13 \mu \mathrm{m})$ decreased, and the MEA based on the thinner PEM gave the lower open circuit voltage (OCV) due to the higher gas cross-over. Thus, the thin PEM based on RX-PTFE had shown a high performance at the suitable thickness.
\end{abstract}

Keywords: PEFC, thin PEM, Radiation grafting, low energy EB

\section{Introduction}

Polymer electrolyte fuel cells (PEFCs) have been developed intensively and the market of PEFCs has been growing for use as the power sources of electric vehicles and for use in stationary co-generation systems [1]. PEFCs are expected to help in reducing our dependence on fossil fuels, and emit no harmful substance in the chemical reaction. However, for familiarizing PEFCs there are some problems to be solved, for example, cost and power generation efficiency.

The cost of proton exchange membrane (PEM) is estimated as $6 \%$ of the PEFC total cost [2]. Nafion ${ }^{\circledR}$ (DuPont Co., Ltd.) is known as the good PEM for the PEFC utilization, but it has high cost. The less cost PEM is expected. In our previous study, PEMs were prepared by EB grafting of styrene onto base fluorinated polymer films, such as PTFE, FEP, etc., followed by sulfonation is designed as an alternative route to the preparation of relatively low cost [3].

Additionally, it is well known that water uptake condition in membrane electrode assemble (MEA) is an important factor for the performance of PEFC [4]. During electric generation, humidity state of PEMs is changed. One is that water is produced through chemical reaction in the cathode area, and the other is that water is transported with proton from anode to cathode area. These phenomena should induce the dry-up around the anode side and should induce the excessive water generation and flooding in the area of the cathode. It has been known that dry-up could cause the decreasing of proton conductivity, and flooding could cause the voltage decreasing due to the inhibition of fuel penetration. Resent work has shown that the performance of PEFC was influenced by many parameters depending on either operating conditions or construction materials which influence the activation, ohmic and mass transport 
losses [5]. Among them, the thinner membrane showed the better the performance, because the resistance to mass transfer of the protons decreases. Moreover, water management may also get easier in thinner membranes [6]. However, the gas cross-over phenomena which are the fuel gases such as $\mathrm{H}_{2}$ and $\mathrm{O}_{2}$ diffused from anode (cathode) to cathode (anode) in MEA, may be easily occurred in thinner PEMs.

In our previous study, the hybrid PEMs and the functionally graded PEMs were demonstrated to control the water uptake in MEA. Hybrid PEMs were prepared by blending fine powders of milled partially fluorinated sulfonic acid membranes (part-FSAs) in Nafion ${ }^{\circledR}$-dispersion (DuPont Co., Ltd.). The result of PEFC performance obtained for the prepared hybrid MEAs indicated that gradient of water uptake in MEAs could significantly control the humidity state in MEA during FC operation [7]. On the other hand, the functionally graded PEMs were prepared by controlling accelerating voltage of EB irradiation in graft polymerization treatment. The EB irradiation to polymer membranes provided gradient energy deposition across the membrane thickness and created gradient of sulfonic acid group. The FC performance of MEA was improved very much at the high current density. It was thought that the water uptake gradation could give a new function to prevent flooding at the cathode areas of the MEA during FC operation [8].

In this study, several thin PEMs based on sulfonated cross-linked PTFE (S-RX PTFE) were fabricated by EB grafting method using low energy EB irradiation, and then the MEAs based on the S-RX PTFEs were prepared by hot pressing. To evaluate the thickness effect, FC performance and electrochemical characteristics were measured. The suitable thickness of PEM based on S-RX PTFE for FC performance is proposed.

\section{Experimental procedure}

2.1 Preparation of the different thickness PEMs

PTFE dispersion $\left(\right.$ FLUON $^{\circledR}$ PTFE AD911E, Asahi Glass Fluoropolymers Co., LTD.) was used for the experiments. The three thicknesses of thin PTFE membranes were prepared by wire-bar coater at atmospheric circumstances (wire-bar No. 9,12,16, coating speed: $16 \mathrm{~mm} / \mathrm{s}$, drying time by Halogen heater: $30 \mathrm{~s}$ ), and were subjected to heat treatment at $80{ }^{\circ} \mathrm{C}$ for $20 \mathrm{~h}$ and $150{ }^{\circ} \mathrm{C}$ for $24 \mathrm{~h}$. After sintering treatment, cross-linked PTFE (RX PTFE) membranes, and PTFE film (Naflon ${ }^{\circledR}$ tape, NICHIAS) with the thickness of $50 \mu \mathrm{m}$, which was used for comparison, were fabricated by $\mathrm{EB}$ (CURETRON $^{\circledR}$, acceleration voltage: $200 \mathrm{kV}$, current: $1 \mathrm{~mA}$, installed at RISE, Waseda University, NHV Corp.) irradiation under the nitrogen atmosphere at $335 \pm 5{ }^{\circ} \mathrm{C}$ [9-11]. The irradiated $\mathrm{RX}$ PTFEs were grafted with styrene by EB irradiation at $15 \mathrm{kGy}$ in the nitrogen atmosphere at room temperature (EB grafting method). The styrene monomer has been grafted onto thin films of RX PTFE in liquid phase at $80^{\circ} \mathrm{C}$ under a vacuum.

The grafting yields were determined as the weight gain of the materials according to the following equation;

Grafting Yield (GY) $(\%)=\frac{W_{g}-W_{0}}{W_{0}} \times 100 \%$

where $W_{g}$ and $W_{0}$ are the weights of the materials after and before grafting, respectively.

The styrene-grafted Cross-linked PTFEs were sulfonated with a micture solution of chlorosulfonic acid and carbontetrachloride $\left(\mathrm{CCl}_{4}\right)$ (1:100 vol.\%) at room temperature with a period of $24 \mathrm{~h}$.

The water uptakes were tested at room temperature and calculated according to the following equation;

$$
\text { Water Uptake (WU) }(\%)=\frac{W_{w}-W_{d}}{W_{d}} \times 100 \%
$$

where $W_{w}$ and $W_{d}$ are the weights of the wet and the dried PEMs, respectively. The labels and properties of the PEMs used in this work are listed in Table 1.

The gas cross-over, permeated oxygen through PEM, with an effective area of $1.0 \mathrm{~cm}^{2}$ was taken by GC-TCD (GC323, GL Sciences Inc.) with dry $\mathrm{O}_{2}$ supplied under $0.2 \mathrm{MPa}$, and gas flow rates were $200 \mathrm{ml} / \mathrm{min}$. Gas holder's size was $50^{\varphi} \times 50 \mathrm{~m} / \mathrm{m}$. The gas cross-over value, which was oxygen density in the nitrogen atmosphere, was evaluated as the criterion of the amount of oxygen in the air.

Table 1 Characteristic property of PEMs

\begin{tabular}{cccc}
\hline Label & $\begin{array}{c}\text { Wet } \\
\text { Thickness } \\
(\mu \mathrm{m})\end{array}$ & $\begin{array}{c}\text { Grafting } \\
\text { Yield } \\
(\%)\end{array}$ & $\begin{array}{c}\text { Water } \\
\text { Uptake } \\
(\%)\end{array}$ \\
\hline S-RX 13 & $13.6 \pm 0.5$ & 46.8 & 41.3 \\
S-RX 18 & $18.6 \pm 1.3$ & 38.3 & 41.9 \\
S-RX 23 & $23.2 \pm 1.1$ & 41.6 & 47.4 \\
S-RX 73 & $73.8 \pm 2.7$ & 40.9 & 50.1 \\
\hline
\end{tabular}


2.2 MEAs preparation and the cell performance

The obtained membranes, sulfonated cross-linked PTFEs (S-RX PTFEs), were laminated with the electrodes (Electro Chem, Inc.) to form MEAs. Carbon electrodes with $1 \mathrm{mg} / \mathrm{cm}^{2}$ platinum loading were coated with Nafion $^{\circledR}$-dispersion and subsequently dried at $80^{\circ} \mathrm{C}$ for $2 \mathrm{~h}$ to form binding layers on the electrodes. S-RX PTFEs were stored in deionized water for $1 \mathrm{~h}$ to obtain good adhesion between the PEM and electrodes. All these MEAs were prepared using press machine (Tester Sangyo Co., LTD.) at $110{ }^{\circ} \mathrm{C}$ during $3 \mathrm{~min}$ with pressure of $0.8 \mathrm{MPa}$.

The MEAs were assembled in to single cell unit with an effective area of $1.0 \mathrm{~cm}^{2}$. Fuel cell performances were obtained at $60{ }^{\circ} \mathrm{C}$ with humidified $\mathrm{H}_{2}$ and dry $\mathrm{O}_{2}$ supplied under $0.2 \mathrm{MPa}$, and both gas flow rates were $50 \mathrm{ml} / \mathrm{min}$. The characterization of MEA was made in terms of polarization performance and electrochemical impedance spectroscopy (EIS) with a HZ-3000 electrochemical analysis system (Hokuto Denko Co.). EIS was measured in the frequency range from $100 \mathrm{kHz}$ to $0.1 \mathrm{~Hz}$ at an ac current density of $500 \mathrm{~mA} / \mathrm{cm}^{2}$.

\section{Results and discussion}

\section{1 gas cross-over}

Figure 1 shows the oxygen gas cross-over of different thickness PEMs. The gas cross-over represented transported fuels through PEM. The thinner PEM had the higher value. This result was understood that because thin PEM decreased barrier of flowing gas.

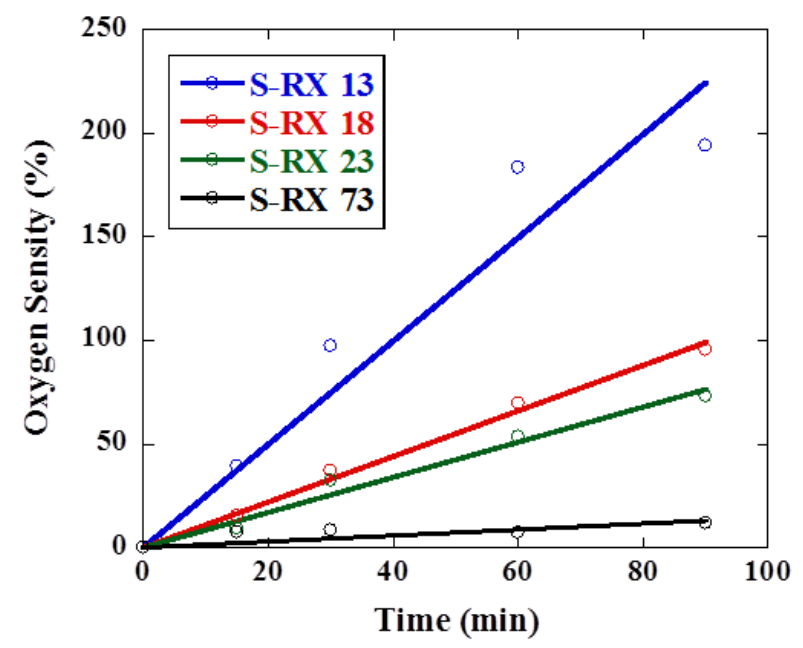

Figure 1. Gas cross-over of different thickness PEM. $\mathrm{O}_{2}$ gas flow: $200 \mathrm{ml} / \mathrm{min}$, gas pressure: $0.2 \mathrm{MPa}$. The lines are for the guide to the tendencies.
Gas cross-over causes not only low efficiency for cell operation but also degraded PEM by potential vulnerability to $\mathrm{H}_{2} \mathrm{O}_{2}$ formed in the cell [12]. Additionally, it was thought that degrade of PEM should be caused by the pinhole, and this pinhole accreted gas cross-over. Gas was diffused in accordance with gas diffusion coefficient, and increase as the inverse square of thickness, generally. However, the values of all S-RX PEM showed the certain inhibition to the $\mathrm{O}_{2}$ penetration, because the network formation in the matrices decrease the diffusion of oxygen thorough the PEM $[13,14]$. The low gas cross-over values were believed to give the benefit on the PEMs under the cell operation. On the other hand, S-RX 13, which was the thinnest PEM, showed a higher value than others. Comparing with PEM based on PTFE dispersion by hand-made, the value for the S-RX 13 was three times higher than that for the S-RX 23. It was thought that S-RX 13 should have more pinholes than others due to deterioration of strength by thickness and difficulty of handling of PEM preparation. And it might be showed that too thin PEM caused difficulty of efficient operation.

\subsection{Cell Performance of the MEAs}

Figure 2 shows the polarization curves of the MEAs at $60{ }^{\circ} \mathrm{C}$ operations (RH $16 \%$ ). The open circuit voltages (OCVs), power densities at 500 $\mathrm{mA} / \mathrm{cm}^{2}$ and maximum are summarized in Table 2.

The MEAs based on the thinner PEM among the S-RX 73 to S-RX 18, showed better performance in

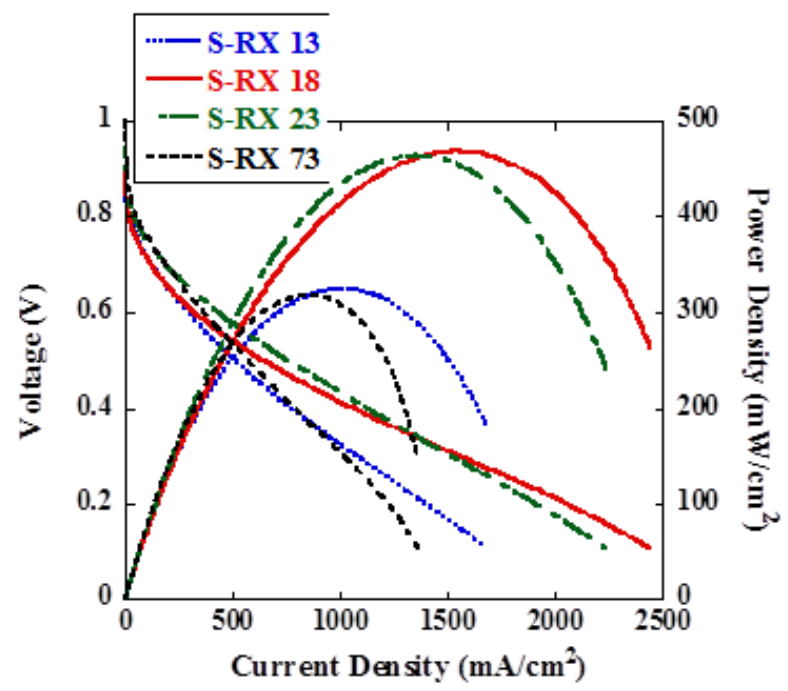

Figure 2. Polarization curves of MEAs based different thickness PEMs. PEM. Cell temperature: $60{ }^{\circ} \mathrm{C}$, $\mathrm{H}_{2} / \mathrm{O}_{2}$ gas flow: $50 \mathrm{ml} / \mathrm{min}$, gas pressure: $0.2 \mathrm{MPa}, \mathrm{H}_{2}$ humidified at $25{ }^{\circ} \mathrm{C}, \mathrm{O}_{2}$ dry, $\mathrm{RH} 16 \%$ 
terms of power densities, and improved at the higher current density range, where diffusion polarization affected on the polarization curve. For example, the maximum power density of obtained MEA based on the S-RX 18 shows $469 \mathrm{~mW} / \mathrm{cm}^{2}$ It would be suggested that thinner PEM has the improved flooding and increased diffusion polarization characteristics, because it should enhance the reveres-diffusion of water, that is, water transportation should occur from cathode to anode. Driving force of reveres-diffusion might be water concentration distribution in PEM under the operation, and thinner PEM had high water concentration distribution in the same condition. The simple approximated water concentration distribution images in the operated PEMs are shown in Figure 3.

On the other hand, S-RX 13, which was thinnest PEM in this study, showed decreased performance, especially in the range of higher current density. And the MEAs based on the thinner PEM showed lower OCV. As the result, the MEA based on thin PEM tended to drive fuel gas cross-over [15]. Excessive gas cross-over caused adverse effects on cell performance. It would be thought that there was technological margin and just leveled surface for the thinned PEM.

Table 2 The dependence of the performance on the difference thickness

\begin{tabular}{cccc}
\hline \multirow{2}{*}{ Label } & \multirow{2}{*}{$\begin{array}{c}c \\
(\mu \mathrm{m})\end{array}$} & \multicolumn{2}{c}{ Power Density $\left(\mathrm{mW} / \mathrm{cm}^{2}\right)$} \\
\cline { 3 - 4 } & @ 500 mA/cm & Maximum \\
\hline S-RX 13 & 853 & 252 & 325 \\
S-RX 18 & 850 & 271 & 469 \\
S-RX 23 & 913 & 289 & 464 \\
S-RX 73 & 953 & 268 & 317 \\
\hline
\end{tabular}

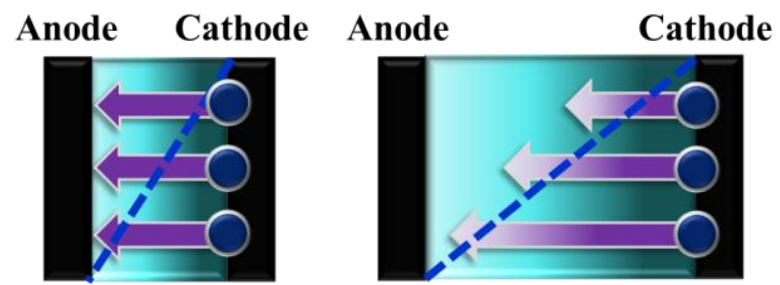

Figure 3. Water concentration distribution image: thin PEM (left) and thick PEM (right).

\subsection{Electrochemical impedance spectra measurements}

Figure 4 shows all the EIS curves of the MEAs at $60{ }^{\circ} \mathrm{C}$ operations ( $\mathrm{RH} 16 \%$ ). All the curves are semicircular. The impedance spectra are quantified using model parameters from an equivalent circuit such as Nyquist presentation [16, 17]. The ohmic resistances $\left(\mathrm{R}_{\mathrm{ohm}}\right)$ values, which are the intersections on the real axis at high frequency, and the charge transfer resistance $\left(R_{c t}\right)$ values, which can be calculated as the diameter of the semicircle on the real axis, are listed in Table 3.

The $R_{\text {ohm }}$ was given by the ionic conductivity of the membrane. The $R_{\text {ohm }}$ of the MEA based on the thin PEMs was lower value than the MEA based on thick PEM. It might be showed that thinned PEM was beneficial in decreasing the ionic conductivity of the membrane.

The $\mathrm{R}_{\mathrm{ct}}$ values of S-RX 18 and S-RX 23 were much lower than that of S-RX 73, thick PEM, and $\mathrm{S}-\mathrm{RX} 13$, thin PEM. The changes in $\mathrm{R}_{\mathrm{ct}}$ values might be flooding. Because S-RX 18 and S-RX 23 had reveres-diffusion of water, it would be that water condition in PEM became leveling and water efficiently eliminated though gas diffusion layer (GDL). On the other hand, S-RX 73 had low reverse-diffusion of water, which caused flooding and high $\mathrm{R}_{\mathrm{ct}}$ value. And the thinnest PEM showed high $R_{c t}$ value, too. It might be thought that it had low distribution concentration differences of water in the PEM and was caused flooding, due to saturation of water. And thinner PEM has decreased mechanical strength, so it may give the space between PEM and GDL.

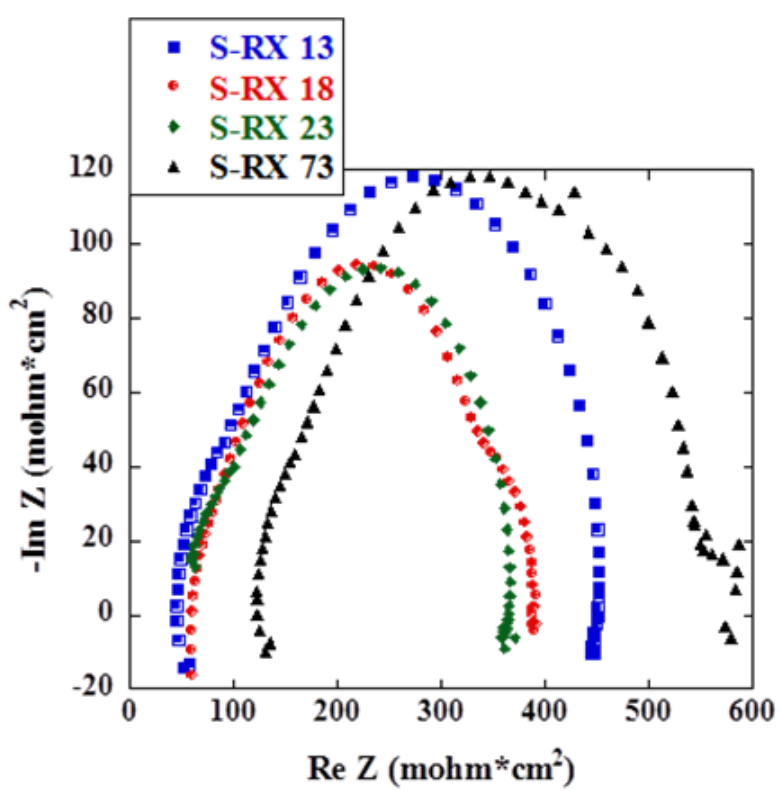

Figure 4. the electrochemical impedance spectra of MEAs based on cross-linked PTFE, measured with ac current densities of $500 \mathrm{~mA} / \mathrm{cm}^{2}$ at $60{ }^{\circ} \mathrm{C}$. 
Table 3 Electrochemical characterization of PEMs.

\begin{tabular}{ccc}
\hline Label & $\mathrm{R}_{\text {ohm }}(\Omega)$ & $\mathrm{R}_{\text {ct }}(\Omega)$ \\
\hline S-RX 13 & 45 & 406 \\
S-RX 18 & 59 & 328 \\
S-RX 23 & 68 & 294 \\
S-RX 73 & 122 & 453 \\
\hline
\end{tabular}

\section{Conclusion}

PEFC membranes based on cross-linked PTFE with different thickness have been fabricated by grafting with styrene monomers using EB irradiation under the nitrogen atmosphere at room temperature, and subsequent sulfonation. Gas cross-over experiments showed that the thinner PEM showed the higher gas cross-over values, especially the value of S-RX 13. The polarization curves and electrochemical impedances of MEA based on S-RX PTFE were analyzed. As a result, the maximum power density for obtained MEA based on the S-RX 18 showed $469 \mathrm{~mW} / \mathrm{cm}^{2}$ at 60 ${ }^{\circ} \mathrm{C}$ operation (RH $16 \%$ ). The MEA based on the thinner PEM has the higher cell performance and smaller $R_{\mathrm{ct}}$ value expect S-RX 13. Thus, the thin PEM based on RX-PTFE had high performance, and there is suitable thickness.

\section{Acknowledgements}

A part of this work is supported by RISE project of Waseda University (11L01).

\section{Reference}

[1] R. K. Shah, in: S. Basu (Ed.), Springer/Anamaya Publishers, NewDelhi, India, 2007, pp.1-9 (Ch.1).

[2] J. Marcinkoski, J. P. Kopasz, T. G. Benjamin, Int. J. Hydrogen Energy 33 (2008) 3894-3902.

[3] S. Asano, F. Mutou, S. Ichizuri, Li. Y. J., T. Miura, A. Oshima, Y. Katsumura, M. Washio, Nuclear Instruments and Methods in Physics Research B 236 (2005) 437-442

[4] Gurser, S.A., Youcef, H.B., Wokaun, A., Scherer, G.G., 2007..Nuclear Instruments and
Methods in Physics Research B 265 (2007), 198-203.

[5] Lin Wang, Attila Husar, Tianhong Zhou, Hongtan Liu, International Journal of Hydrogen Energy 28 (2003) 1263 - 1272.

[6] Ayşe Bayrakçeken, Serdar Erkan, Lemi Türker, Inci Ero glu, International Journal of Hydrogen Energy 33 (2008) 165 - 170.

[7] Sato, Y., Fujii, K., Mitani, N., Matsuura, A., Kakigi, T., Muto, F., Li,J.Y., Oshima, A., Washio, M., Nuclear Instruments and Methods in Physics Research B 265 (2007), 213-216.

[8] H. Fujita, F. Shiraki, Y. Oshima, T. Tatsumi, T. Yoshikawa, T. Sasaki, A. Oshima, M. Washio, Radiation Physics and Chemistry 80 (2011) 201-206

[9] S. Asano, F. Mutou, S. Ichizuri, J.Y. Li, T. Miura, A. Oshima, Y. Katsumura, M. Washio, Nuclear Instruments and Methods in Physics Research B 236 (2005) 437.

[10] A. Oshima, T. Miura, S. Asano, S. Ichizuri, J.Y. Li, S. Ikeda, M. Iida, C. Matsuura, Y. Tabata, Y. Katsumura, M. Washio, Research of Chemical Intermedates 31 (2005) 585.

[11] A. Oshima, T. Hyuga, S. Asano, F. Mutou, S. Ichizuri, J.Y. Li, T. Miura, M. Washio, Nuclear Instruments and Methods in Physics Research B 236 (2005) 172.

[12] T. Kinumotoa, M. Inabaa, Y. Nakayamaa, K. Ogataa, R. Umebayashia, A. Tasakaa, Y. Iriyamab, T. Abeb, Z. Ogumib, Journal of Power Sources 158 (2006)1222-1228.

[13] Japan Atomic Energy Research Institute, JAERI report 1299

[14] F. Muto, Master Thesis of Waseda University, 2005

[15] Vilekar, S.A., Datta, R., Journal of Power Sources 195 (2010) 2241-2247.

[16] P. M. Gomadam, J. W. Weinder, International Journal of Energy Research 29 (2005) 1133-1151.

[17] Technical notes, Fuel cell performance and the characterization methods (in Japanese), NF Corp. Japan. 